\title{
NATO SYSTEM ANALYSIS AND STUDIES PANEL
}

\section{Roger FORDER}

The NATO Research and Technology Organisation (RTO) promotes and conducts co-operative scientific research and exchange of technical information amongst 28 NATO nations and 38 NATO partners. The largest such collaborative body in the world, the RTO encompasses over 3000 scientists and engineers addressing the complete scope of defence technologies and operational domains. This effort is supported by an executive agency, the Research and Technology Agency (RTA), that facilitates the collaboration by organising a wide range of studies, workshops, symposia, and other forums in which researchers can meet and exchange knowledge.

The Research \& Technology Board (RTB) constitutes the highest authority within the RTO, and is the policy body tasked by the North Atlantic Counsel (NAC) through the Conference of National Armaments Directors (CNAD) and Military Committee (MC) to carry out the mission of the RTO.

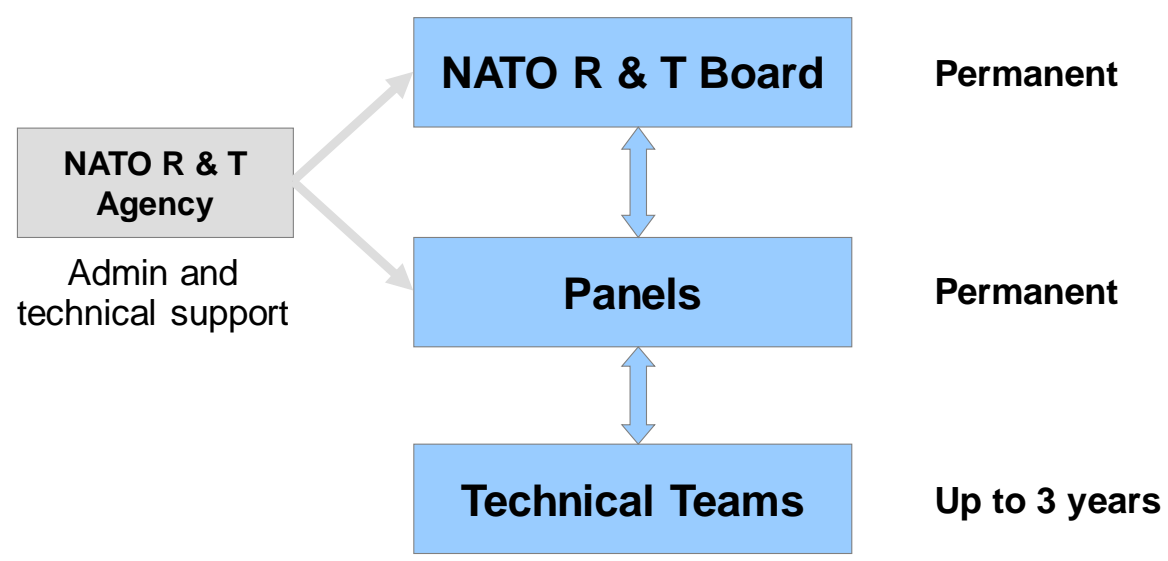

Figure 1: NATO Research and Technology Organisation. 
There are seven NATO RTB Panels / Group:

- $\quad$ System Analysis and Studies Panel

- Systems Concepts and Integration Panel

- Human Factors and Medicine Panel

- Advanced Vehicle Technology Panel

- Information Systems Technology Panel

- Sensors and Electronics Technology Panel

- $\quad$ NATO Modelling and Simulation Group.

The mission of the System Analysis and Studies (SAS) Panel is:

- To conduct studies and analyses of an operational and technological nature, and

- To promote the exchange and development of methods and tools for operational analysis as applied to defence problems.

The SAS Panel Scope:

The Panel will conduct studies, analysis and information exchange activities that explore how operational capability can be provided and enhanced through the exploitation of new technologies, new forms of organisation or new concepts of operation. Such studies will, where appropriate, give explicit consideration to financial and other resource issues. The Panel will be responsive to requests for such studies from a variety of sources, including nations, the R\&T Board, the Military Committee, CNAD, the Main Armaments Groups, ACT, ACO, NC3A, NIAG and industry. The Panel can also perform studies of a more purely technological nature if such studies are not appropriate for another NATO body.

The Panel will undertake activities to develop and promote improved analysis methods and techniques to support defence decision-making. This aspect of the Panel's work will focus particularly on the methods required to address the new issues thrown up by the evolving strategic environment and the responses that both individual nations and NATO as a whole are making to it. Activities may include information exchange on OA modelling concepts and best practice, research into new methodological approaches and the development and exchange of models.

The SAS Panel meets twice a year. The Panel reviews work in progress and completed work; considers proposals for new Technical Teams (TT) from nations and NATO bodies; recommends forward programme to RTB; etc. A technical team may be a task group, specialist team, symposium, specialists' meeting, workshop, or lecture series. New TT requires at least four member nations to participate. Partnership for Peace nations may be invited to participate. Other nations can participate if 'sponsored' by a NATO nation and Panel and RTB approve (only example so far is Aus- 
tralia). TT proposals are usually refined by one or two meetings of an informal 'Exploratory Team.'

Below the reader may find extract from current SAS Panel programme:

- Multinational Logistics

- Human Resource Management

- Non-Lethal Weapons Effectiveness Assessment Development and Verification

- Defence against CBRN Attacks in the New NATO Strategic Environment

- Impact of Potentially Disruptive Technologies

- Benchmarking Studies and Capability Costing

- Modelling NATO NEC

- Joint Operations 2030

- Lecture Series on Effects-Based Approach to Operations

- Code of Best Practice on Life-Cycle Costing. 